\title{
Ablation laser en fond de cratère
}

\author{
F. Garrelie, C. Girault, B. Angleraud, C. Champeaux et A. Catherinot
}

URA 320 du CNRS "Matériaux Céramiques et Traitements de Surface", Equipe "Plasma - Laser - Matériaux", Faculté des Sciences, 123 avenue Albert Thomas, 87060 Limoges cedex, France

\begin{abstract}
Résumé : Cet article est consacré à l'observation à l'aide d'une caméra C.C.D. intensifiée du panache plasma créé lors de l'ablation en fond de cratère d'une cible de verre par un laser à excimères $\mathrm{KrF}$. L'influence de la profondeur du cratère a été suivie en fonction de la pression ambiante.
\end{abstract}

Le dispositif d'imagerie utilisé est composé d'un objectif Nikkon de focale $105 \mathrm{~mm}$ et de domaine spectral visible $(300-800 \mathrm{~nm})$ monté sur un détecteur C.C.D. intensifié. Chaque image représente le panache plasma créé au fond du cratère à un temps donné après le début de l'impulsion laser. Le cratère est obtenu en effectuant une série de tirs laser successifs sur la cible.

Deux profondeurs de cratère ont été étudiées : $0,5 \mathrm{~mm}$ (ce qui correspond à 300 impulsions laser) et $4,7 \mathrm{~mm}$ (5700 tirs laser). L'expansion du panache a été suivie pour différentes pressions résiduelles dans l'enceinte $(10 \mathrm{~Pa}, 50 \mathrm{~Pa}$ d'argon, $200 \mathrm{~Pa}$ d'argon et sous air à pression atmosphérique). Cette étude a été effectuée à une fluence laser d'environ $80 \mathrm{~J} / \mathrm{cm}^{2}$ et avec une durée d'intensification du détecteur fixée à 5 ns.

La figure 1 représente le panache plasma à différents délais après le début de limpulsion (100 $\mathrm{ns}, 400 \mathrm{~ns}$ et $1 \mu \mathrm{s}$ ) lorsque la pression résiduelle d'argon dans l'enceinte est de $50 \mathrm{~Pa}$. Pour une profondeur de cratère de $0,5 \mathrm{~mm}$ (figure 1a), l'aspect du panache n'est pas très différent de celui observé lorsque le panache plasma est créé en surface [1]. Une profondeur de cratère plus importante $(4,7 \mathrm{~mm}$ : figure $1 \mathrm{~b})$ conduit à un changement d'aspect du panache qui est "guidé" dans la direction du cratère. L'expansion est monodirectionnelle jusqu'à un délai de $400 \mathrm{~ns}$ après le début de l'impulsion laser, le panache prend ensuite la forme d'un croissant caractéristique de la formation d'une onde de choc. Seul l'aspect qualitatif du panache est modifié ; la vitesse d'expansion du front du panache est la même quelle que soit la profondeur du cratère $(0,5 \mathrm{~mm}$ ou $4,7 \mathrm{~mm})$. Pour une pression ambiante inférieure ou égale à $50 \mathrm{~Pa}$, l'ablation en fond de cratère n'induit donc qu'un changement de la forme d'expansion du panache.

La même étude a été réalisée pour une pression ambiante d'argon de $200 \mathrm{~Pa}$. Les images de la bulle plasma sont reportées sur la figure 2 . Le même changement d'aspect du panache est observé lorsque la profondeur du cratère varie de $0,5 \mathrm{~mm}$ (figue $2 \mathrm{a}$ ) à $4,7 \mathrm{~mm}$,(figure $2 \mathrm{~b}$ ). Du fait de l'augmentation de la pression ambiante, le plasma semble plus confiné près de la surface que lors de l'étude à une pression ambiante d'argon de $50 \mathrm{~Pa}$ [2].

Cependant, on note un changement important dans les dimensions du panache. En effet, pour une profondeur de cratère de $0,5 \mathrm{~mm}$, la hauteur maximale atteinte par le panache est de $9 \mathrm{~mm}$ alors que pour une profondeur de cratère de $4,7 \mathrm{~mm}$, elle est de $16 \mathrm{~mm}$. Le cratère semble jouer le rôle d'un canon, ce qui tendrait à diminuer linfluence de la pression ambiante et donc à retarder l'instant où la bulle est "stoppée" par les particules du gaz ambiant. 
En résumé, on constate que :

- Quelle que soit la pression ambiante à laquelle s'effectue l'ablation en fond de cratère, la durée de détection du signal est diminuée lorsque la profondeur du cratère augmente. Ceci est probablement du à la désexcitation de particules émettrices sur les parois du cratère. De plus, un changement d'aspect du panache est observé : le panache créé au fond d'un cratère subit une expansion d'autant plus monodirectionnelle que le cratère est profond.

- Lorsque la pression ambiante est élevée (200 Pa), à ce changement s'ajoute une augmentation des dimensions du panache avec la profondeur du cratère.

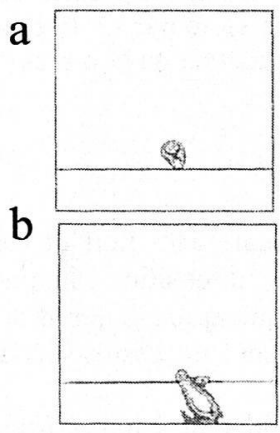

$100 \mathrm{~ns}$

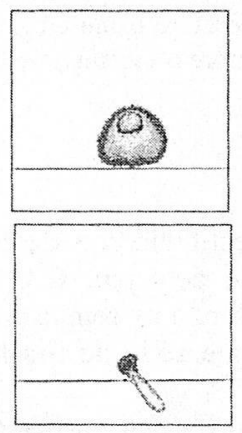

$400 \mathrm{~ns}$

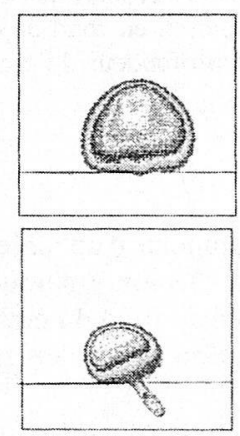

$1 \mu s$

Figure 1: Images du plasma créé en fond de cratère sous une pression ambiante de $50 \mathrm{~Pa}$ d'argon à différents délais après le début de l'impulsion laser pour 2 profondeurs de cratère
a) $0,5 \mathrm{~mm}$
b) $4,7 \mathrm{~mm}$

Taille de l'image : hauteur $=2,6 \mathrm{~cm}$; largeur $=2,7 \mathrm{~cm}$.

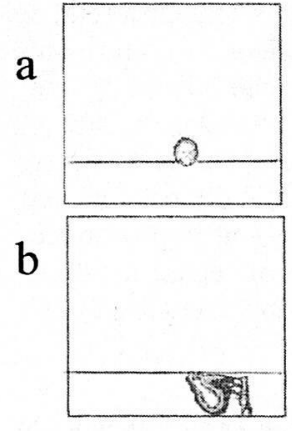

$100 \mathrm{~ns}$
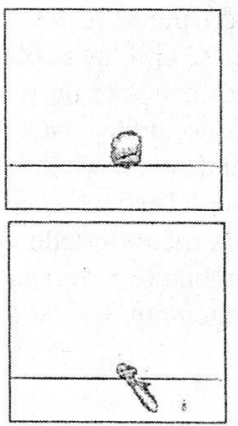

$400 \mathrm{~ns}$
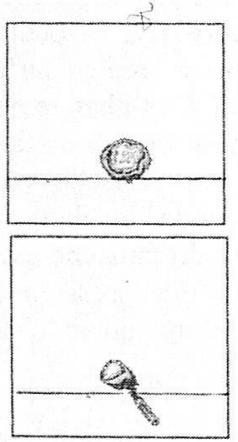

$1 \mu \mathrm{s}$

Figure 2: Images du plasma créé en fond de cratère sous une pression ambiante de 200 Pa d'argon à différents délais après le début de l'impulsion laser pour 2 profondeurs de cratère
a) $0,5 \mathrm{~mm}$
b) $4,7 \mathrm{~mm}$

Taille de l'image : hauteur $=2,6 \mathrm{~cm}$; largeur $=2,7 \mathrm{~cm}$.

[1] B. ANGLERAUD, Thèse de doctorat de l'université de Limoges, 9 Nov 1995.

[2] D. B. GEOHEGAN, Appl. Phys. Lett. 60 (22), 2732 (1992). 